\title{
Medical and Clinical Case Reports
}

\section{Diagnostic and Therapeutic Modalities of Lumbar Hernia: About A Case}

\section{Dyatta Mayombo K ${ }^{1,2 *}$, Ipouka Doussiemou S', Nguele Ndjota1,2, Orendo Sossa J', Oparadji JR', Mvé Ndong BF ${ }^{1}$, Diallo Owono $\mathrm{FK}^{1,2}$ and Ondo N'Dong $\mathrm{F}^{1,2}$}

\author{
${ }^{1}$ Department of Visceral and General Surgery, University Hospital \\ Center of Libreville, Gabon.
}

${ }^{2}$ Department of Surgery, Faculty of Medicine, University of Health Sciences of Owendo Libreville, Gabon.

\section{"Correspondence:}

Dr Kévin Dyatta Mayombo, Master-Assistant in General Surgery, Department of Visceral and General Surgery, University Hospital Center of Libreville, Gabon, Tel: +241 66232267.

Received: 27 April 2021; Accepted: 20 May 2021

Citation: Dyatta Mayombo K, Ipouka Doussiemou I, Nguele Ndjota et al. Diagnostic and Therapeutic Modalities of Lumbar Hernia: About A Case. Med Clin Case Rep. 2021; 1(1): 1-3.

\begin{abstract}
Introduction: Lumbar hernias are rare. They are done either through the lower and superficial lumbar triangle of Jean-Louis Petit, or through the upper and deep lumbar quadrilateral of Grynfeltt. They can be primary or secondary. We report a rare case of primary hernia of Jean-Louis Petit.

Observation: Mrs. M.A, 73 years old, with a surgical history of right herniorrhaphy indicated in front of an uncomplicated right inguinal hernia, consulted for a right lumbar discomfort. Clinical examination found mild obesity, painless right lumbar swelling above the iliac crest, soft, impulsive to cough, manually reducible. The ultrasound revealed a dorsal lipoma. The scanner was not performed. The diagnosis of lumbar hernia was retained due to the characteristics of the swelling. She received an open prosthetic hernia repair. The post-operative consequences were simple. There was no recurrence after a year.
\end{abstract}

Conclusion: Lumbar hernias are rare. The clinical examination guides the diagnosis. Its treatment is based on surgery. The open route remains the most affordable in our community. The prosthetic treatment gives good results.

Keywords

Lumbar hernia, Open approach, Prosthesis.

\section{Introduction}

Lumbar hernias are rare, 200 to 300 published cases are listed in the literature [1]. They are made through two weak areas of the posterolateral abdominal wall: the quadrilateral of Grynfeltt and the triangle of Jean-Louis Petit.

Through this rare case of lumbar hernia operated on at the Department of Visceral Surgery of the University Hospital of Libreville, the authors propose to highlight the diagnostic difficulties and to discuss the modalities of surgical treatment during this affection.

\section{Patient and Observation}

Mrs. M.A, 73 years old had been consulting for a right lumbar discomfort evolving intermittently for 4 years. She was the mother of 8 children. She had a surgical history of right hernioraphia indicated in front of an uncomplicated right inguinal hernia. The clinical examination revealed mild obesity with BMI of $31.9 \mathrm{~kg} /$ $\mathrm{m}^{2}$, and on palpation of the right lumbar region a soft, painless, impulsive swelling and expansive to the cough, reducible manually.

Ultrasound of the area was in favor of a lipoma, contrasting with the clinical examination. Without taking into account the ultrasound result and considering the characteristics of the swelling, we retained the diagnosis of lumbar hernia. The indication for parietoplasty was retained.

The patient was installed in the left lateral decubitus (Figure 1) under general anesthesia. After skin incision and dissection of the subcutaneous cell tissue, we observed a large hernial sac and weakness of the muscle structures (Figure 2). The hernial sac was forced back into the abdominal cavity and the defect closed with a $2 / 0$ absorbable suture suture. We had placed a 
macroporous Polypropylene $\AA$ plate in the retro-muscular preperitoneal position (Figure 3 ) and a Delbet blade was placed. The post-operative consequences were simple. Delbet blade ablation was performed on D2 postoperative. The patient was discharged on D3 postoperative and was followed regularly. There was no recurrence after 1 year.

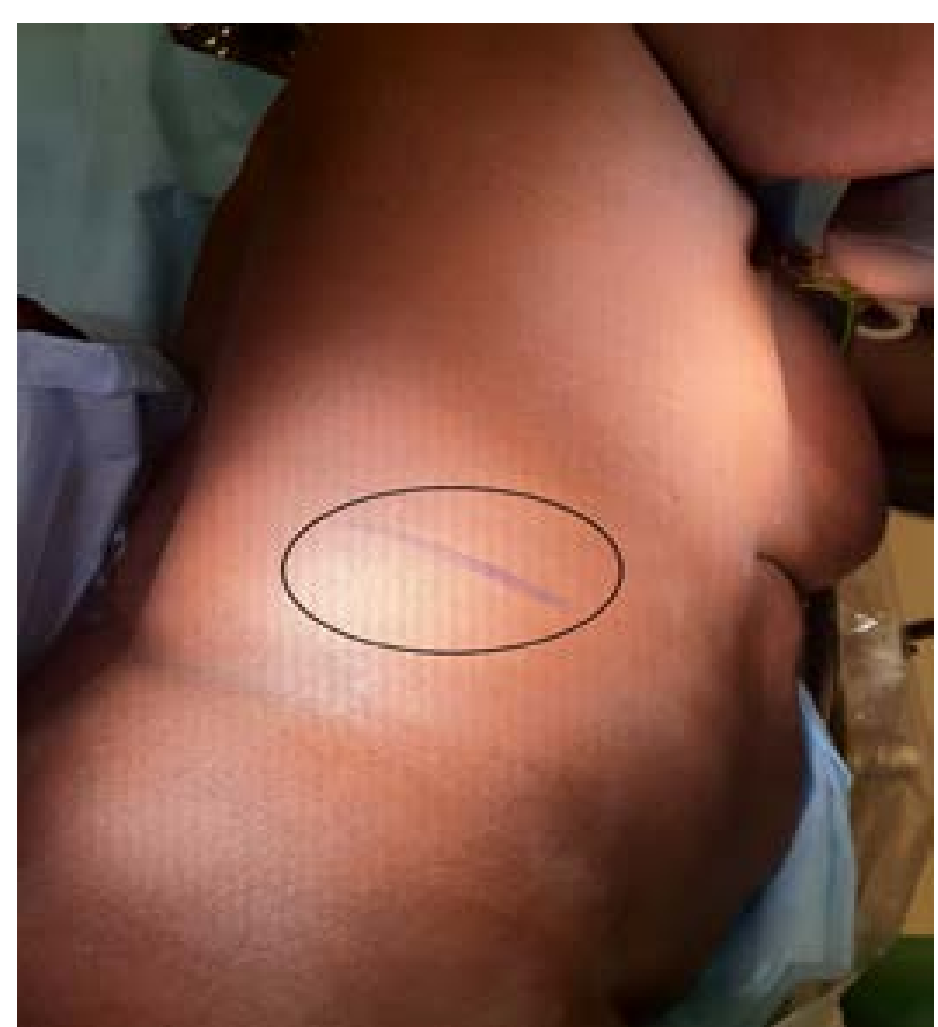

Figure 1: Positioning of the patient on the operating table in the left lateral decubitus position. Marking of the incision line straddling the lumbar swelling (circled).

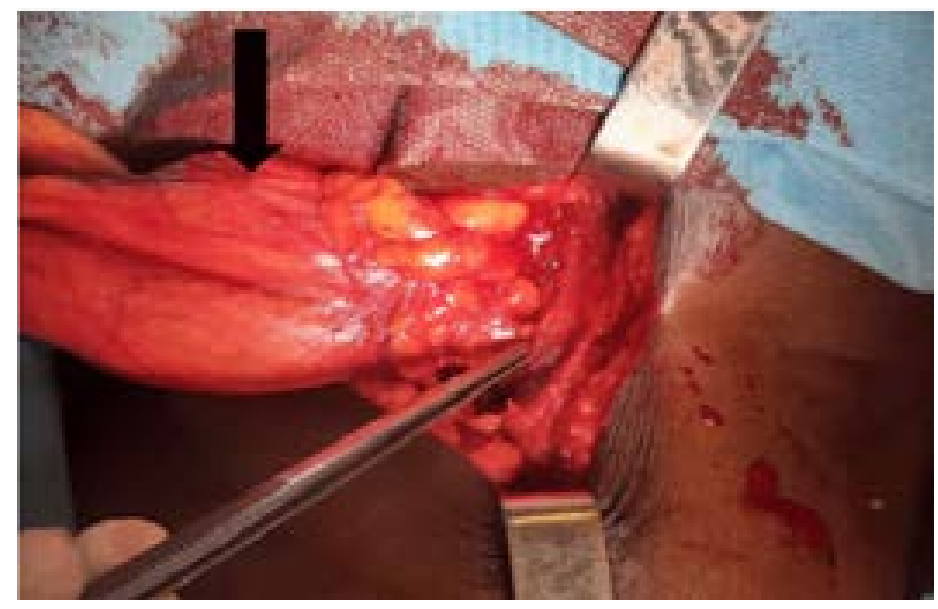

Figure 2: Intraoperative view. Demonstration of the hernial sac with fatty content (black arrow) coming out of the neck (forceps).

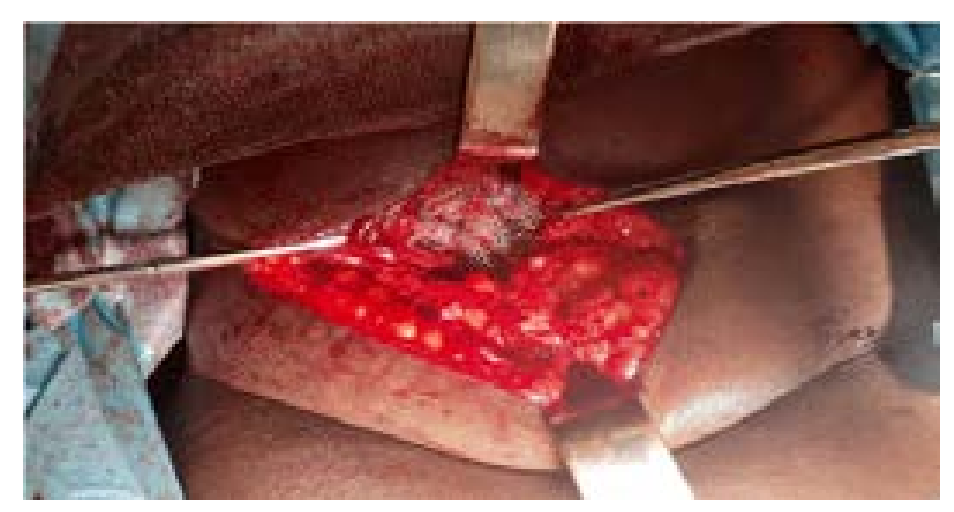

Figure 3: Intraoperative view. Placement of a polypropylene mesh prosthesis in the retro-muscular pre-peritoneal position.

\section{Discussion}

Lumbar hernias are rare entities compared to other abdominal wall hernias. About 300 cases have been published since their discovery by Garangeot in 1731 [1]. The aetiologies of lumbar hernias are well known: a distinction is made between more rare congenital hernias $(20 \%)$ and acquired hernias $(80 \%)$ [1]. Acquired hernias can be classified as primary hernias and secondary hernias. Primary hernias, as in our case, are hernias of weakness resulting from abdominal hyperpressure (chronic cough, obesity, strength work) [2]. Lumbar hernias most often exteriorize through Grynfeltt's upper lumbar quadrilateral because it is the deepest and must necessarily be crossed first for the hernia to pass through Petit's lower triangle; the inferior lumbar hernia cannot exist without the superior lumbar hernia [1].

The diagnosis of a lumbar hernia can be a real challenge. Diagnosis can be difficult in obese patients where the swelling is masked by abdominal fat [2]. Its rarity results in its being ignored by some surgeons and radiologists who most often confuse it with a lipoma [3], as happened in our case. It is therefore necessary to eliminate the various differential diagnoses such as lipoma, a renal mass, a retro-peritoneal mass. The diagnosis of lumbar hernia can be clinical based on the characteristics of the swelling. If there is strong doubt about the diagnosis, it may be necessary to perform an abdominal CT scan. Indeed, it specifies the lesions by showing the neck and the contents of the hernia [4].

The treatment of lumbar hernia is surgical. The open route is the most widely used in Africa [2,5,6]. Lumbar hernia surgery can be done laparoscopically with all the benefits it offers. Since the first case published in 1996 at least 36 cases of laparoscopic treatment have been published [1]. Biance et al. [7] in France took this approach.

The contents of the bag are varied. Baraket et al. [4] found retroperitoneal fat, Attolou et al. [2] found the greater omentum and Mgbakor et al. [3] objectified the colon.

The surgical procedure is done in 2 stages. The treatment of the bag which can be done by ligation and resection of the bag or by repression. Attolou et al. [2] and Tounkoura et al. [6] performed the 
resection of the sac. Lebeau et al. [5] and Baraket et al. [4] took the same approach as our team by pushing back the bag. Repairing the sac should ideally be done by placing a prosthesis extraperitoneally according to evidence-based studies [8]. Baraket et al. [4] used this technique. The lack of prosthetic material sometimes forces us to use raffia, as described by Attolou et al. [2], Lebeau et al. [5] and Tounkoura et al. [6].

Rare recurrences in postoperative lumbar hernias operated by prosthesis [9]. Dinganga Kapessa et al. reported a case of recurrence at 3 years [10].

\section{Conclusion}

In front of a lumbar swelling, it is necessary to know how to think of a lumbar hernia. Its diagnosis is clinical based on the characteristics of the swelling. The treatment is surgical. The open way and the raffies still frequently used in Africa. In the future, they must give way to the use of the laparoscopic route and prosthetic materials for better results.

\section{References}

1. Pélissier E, Habib E, Armstrong O. Traitement chirurgical des hernies lombaires. EMC-Techniques chirurgicales-Appareil digestif. 2010: 40-152.

2. Attolou SG, Meli Momene B, Gandji W, Et al. Hernie lombaire du triangle inférieur: une forme rare de hernie pariétale à propos d'un cas au Centre National Hospitalier et Universitaire Hubert Koutoukou Maga de Cotonou. J Soc Biol Clin Bénin. 2018; 95-98.

3. Mgbakor AC, Bami G, Barthe L, et al. Les difficultés diagnostiques des hernies lombaires à propos de 7 cas. Med Afr. 1999; 46: 334-336.

4. Baraket O, Berriche A, Zribi R, et al. Les hernies lombaires. Analyse de 3 cas. Tunis Med. 2011; 89: 644-646.

5. Lebeau R, Diane B, Assamoi Kassi FB, et al. Les hernies de Jean-Louis Petit: difficultés diagnostiques et thérapeutiques à propos d'un cas. Med Af Noire. 2011 ; 58: 9-13.

6. Tounkoura I, Ongoiba O, Kanté A, et al. Hernie de Grynfeltt au CHU Gabriel Touré à propos d'un cas. Mali Med. 2020; 35: $50-51$.

7. Biance N, Hardwigsen J, Morera P, et al. Hernie du triangle de Jean-Louis Petit: intérêt de la réparation par voie coelioscopique. J Chir. 2006; 143: 199-201.

8. Patnaik S, Nayak TN, Patro S. Lumbar hernia: a case report and review of literature. Int J Sci Study. 2015; 3: 188-190.

9. Williams NS, Bulstrode CJK, O'Connell PR. Bailley and Love's Short Practise of surgery. $26^{\text {th }}$ edition. CRC Press. 2013; 633.

10. Dinganga Kapessa N, Mouteba Katambwa P, Tshibwid Zeng F, et al. Récidive d'une hernie primaire de Jean-Louis Petit : à propos d'un cas. Pan Afr Med J. 2019; 33: 247. 